Article

\title{
Production of Bioactive Compounds by Food Associated Galactomyces geotrichum 38, as Determined by Proteome Analysis
}

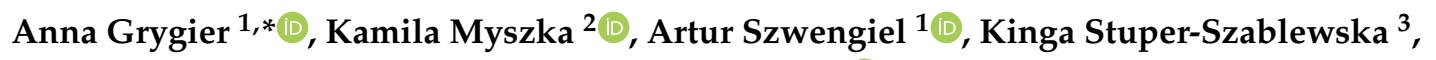 \\ Joanna Pawlicka-Kaczorowska ${ }^{2}$, Grażyna Chwatko ${ }^{4}$ (i) and Magdalena Rudzińska ${ }^{1}$ \\ 1 Institute of Food Technology of Plant Origin, University of Life Sciences, Wojska Polskiego 31, \\ 60-624 Poznań, Poland; artursz@up.poznan.pl (A.S.); magdar@up.poznan.pl (M.R.) \\ 2 Department of Biotechnology and Food Microbiology, University of Life Sciences, Wojska Polskiego 48, \\ 60-627 Poznań, Poland; kmyszka@up.poznan.pl (K.M.); joannap@up.poznan.pl (J.P.-K.) \\ 3 Department of Chemistry, University of Life Sciences, Wojska Polskiego 75, 60-625 Poznań, Poland; \\ kstuper@up.poznan.pl \\ 4 Department of Environmental Chemistry, University of Łódź, Pomorska 163, 90-236 Łódź, Poland; \\ grazyna.chwatko@chemia.uni.lodz.pl \\ * Correspondence: ankaje@gmail.com; Tel.: +48-61-8487276; Fax: +48-61-8487314
}

Received: 12 January 2019; Accepted: 19 February 2019; Published: 23 February 2019

\begin{abstract}
Fried cottage cheese is a dairy product, popular in some parts of Poland. Proteomic analysis of a culture of the mold Galactomyces geotrichum 38 isolated from fried cottage cheese was performed using UHPLC/MS. From the proteins identified, we selected those involved in the biosynthesis of bioactive compounds and those useful in industry. In the G. geotrichum 38 culture, the production quantities of vitamin $B_{2}(224 \mu \mathrm{g} / \mathrm{L})$, ergosterol $(54.63 \mathrm{mg} / \mathrm{kg})$, and trehalose $(0.91 \mathrm{~g} / \mathrm{L})$ were determined by HPLC. The identified proteins were also used to prepare a hypothetical fatty acid biosynthesis pathway, and the percentage of individual sphingolipids in the culture was determined. Sphingolipids are also bioactive compounds. During culturing of G. geotrichum 38, the percentage of three sphingolipids increased. The last step of the research was to prepare a model of fried cottage cheese. The mold G. geotrichum 38, used in the process of ripening fried cottage cheese, synthesized vitamin $B_{2}$ and erogsterol, which influenced the nutritional value of the product.
\end{abstract}

Keywords: G. geotrichum; ergosterol; vitamin $\mathrm{B}_{2}$; trehalose; protein analysis

\section{Introduction}

Many microorganisms are capable of producing bioactive compounds [1], and only some of these possibilities are currently known. The mold Galactomyces geotrichum, or G. geotrichum, is a little-known microorganism that is used as a starter or nonstarter culture in the production of many cheeses throughout the world [2]. The literature indicates that G. geotrichum is capable of producing peptides that inhibit angiotensin I converting enzyme [3] and polyunsaturated fatty acids (PUFA) [4].

Proteomics is an approach that can help in understanding the ability of a microorganism to produce bioactive compounds. Proteomics involves the analysis of the composition, structure, and function, of proteins and of the interactions that take place between them. Such research can be carried out to identify microbial strains, to analyze proteins, and to find factors determining pathogenicity and interactions with the host. Such information about proteins can lead to knowledge of the microorganism's ability to produce bioactive compounds [5]. There are no reports in the literature describing the proteome of G. geotrichum, but on the basis of the proteomics carried out on G. geotrichum 38, the mold's ability to biosynthesize vitamin B2, ergosterol, sphingolipids, and lipoic 
acid was analyzed. Vitamin $B_{2}$ is an important component that affects the proper functioning of the eye and has a role in amino acid and fat metabolism [6,7]. Another bioactive compound that can be produced by microorganisms is ergosterol, the main precursor to cortisone and the hormone progesterone [8]. Sterols are important in bone metabolic processes and in the regulation of calcium homeostasis [9]. Balanced sterols in the diet ensure optimal functioning of many organs and systems, including the kidneys, skin, skeletal muscles, cardiovascular system, immune system, nervous system, and endocrine systems [10]. Publications on ergosterol are most often associated with the study of the contamination of grain by fungi.

Other bioactive compounds include sphingolipids, which are structural elements of the biological membranes of eukaryotic microbes [11]. They also participate in the control of autophagy, which occurs during thermal stress [12]. Sphingolipids inhibit colon carcinogenesis and regulate cholesterol levels [13]. Lipoic acid is a cofactor widespread in the majority of prokaryotic and eukaryotic microorganisms, as well as in plant and animal tissues [14]. It is endogenously synthesized in the liver, though not in sufficient quantities to meet the body's needs. Lipoic acid has a role in the treatment of diseases in which free radicals are important for membrane phospholipids (e.g., liver diseases, neurological disorders, and diabetes). It is a universal antioxidant under conditions of oxidative stress [14]. Some microorganisms also produce trehalose, a saccharide made of two molecules of glucose. This compound has no reducing properties, which allows it to be used in food technology for sweetening products that will be subjected to heat treatment, as it does not cause browning reactions [15]. In molds, trehalose is a component of the cell membrane and occurs as a spare saccharide, while also stabilizing proteins [16].

G. geotrichum 38 is capable of producing bioactive compounds. In our study, proteomic analysis identified the enzymes used by G. geotrichum 38 to biosynthesize bioactive compounds. The potential of G. geotrichum 38 to biosynthesize sphingolipids, vitamin B2, ergosterol, and trehalose has not yet been studied. The production of bioactive compounds by G. geotrichum 38 can be used to prepare fried cheese enriched with bioactive compounds due to the presence of G. geotrichum 38 .

\section{Material and Methods}

\subsection{Reagents}

Potassium phosphate, potassium chloride, glycerol, bicinchoninic acid, Triton X-100, sodium deoxycholate, trypsin, chloroform, methanol, ammonium formate, formic acid, acetonitryle, pentane, tris-(2-carboxyethyl) phosphine, hydrochloride (TCEP), acetic acid, vitamin $\mathrm{B}_{12}$, sulfuric acid (II), ergosterol, lipoic acid and vitamin $\mathrm{B}_{2}$ standard were procured from Sigma Aldrich (Saint Louis, MO, USA). A solution of $1 \mathrm{M}$ potassium hydroxide in methanol was purchased from Fluka (Saint Louis, MO, USA). Chloric acid (VII) was obtained from J.T. Baker (Denventer, Netherlands). Glucose, $\mathrm{MgSO}_{4}, \mathrm{ZnSO}_{4}, \mathrm{FeSO}_{4}, \mathrm{HCl}$ and $\mathrm{NaOH}$ were purchased from Avantor (Gliwice, Poland). Yeast extract was obtained from BD (NJ, USA). $\mathrm{K}_{2} \mathrm{HPO}_{4}$ was purchased from PPH Standard (Lublin, Poland). $\mathrm{MnSO}_{4}$ was procured from Chempur (Piekary Śląskie, Poland). 1-benzyl-2-chloropyridinium bromide (BCBP) was synthesized in the Department of Environmental Chemistry, University of Łódź, in accordance with the procedure described in Bald et al. [17]. Rapeseed oil (ZT Kruszwica S.A., Kruszwica, Poland) was purchased at a local market.

\subsection{Microorganisms and Cultures}

The organism used in this study, G. geotrichum 38, has been described by Grygier et al. [3]. For the first proteomic analysis, G. geotrichum 38 was cultured on a medium in $250 \mathrm{~mL}$ flasks (glucose $2 \%$, yeast extract 1\%) [18]. The culture was grown under dynamic conditions (100 rpm) at $30{ }^{\circ} \mathrm{C}$ for $96 \mathrm{~h}$. For the second proteomic analysis, the culture was grown in a Biostat A plus bioreactor (Sartorius, Gottingen, Germany) with a capacity of $5 \mathrm{~L}$. The cultivation was carried out under dynamic conditions (100 rpm) at $30^{\circ} \mathrm{C}$ for $214 \mathrm{~h}$. The cultures were aerated at an intensity of $1.5 \mathrm{vvm}$ (gas volume flow 
per unit of liquid volume per minute). The $\mathrm{pH}$ value of the environment was 6.5. The medium consisted of $10 \mathrm{~g} / \mathrm{L}$ rapeseed oil, $5 \mathrm{~g} / \mathrm{L}$ yeast extract, $0.05 \mathrm{~g} / \mathrm{L} \mathrm{K}_{2} \mathrm{HPO}_{4}, 0.17 \mathrm{~g} / \mathrm{L} \mathrm{MgSO} 4,0.015 \mathrm{~g} / \mathrm{L}$ $\mathrm{MnSO}_{4}, 0.015 \mathrm{~g} / \mathrm{L} \mathrm{ZnSO}_{4}, 0.05 \mathrm{~g} / \mathrm{L} \mathrm{FeSO}_{4}$, and $10 \mathrm{mg} / \mathrm{L}$ vitamin B12. The above culture conditions stimulated the biosynthesis of PUFA by G. geotrichum 38. To prevent contamination of the cultures, $100 \mu \mathrm{L}$ cultures were placed on Petri dishes and incubated at $30^{\circ} \mathrm{C}$ once every two days. The Petri dishes were monitored for the presence of contamination.

\subsection{Identification of Proteins Produced by G. geotrichum 38}

The supernatant obtained from the G. geotrichum 38 culture was filtered through a $0.45 \mu \mathrm{m}$ filter (GVS Filter Technology, Roma, Italy). The samples were concentrated five times on an Amicon filter (Merck Millipore, Burlington, MA, USA), washing the filter ten times with a buffer consisting of $25 \mathrm{mM}$ potassium phosphate solution, $100 \mathrm{mM}$ potassium chloride solution at $\mathrm{pH} 7.0$, and $10 \%$ glycerol solution. The condensed supernatant was analyzed by sodium dodecyl sulfate polyacrylamide gel electrophoresis (SDS-PAGE). The protein concentration in the assay was determined by the spectrophotometric method using bicinchoninic acid (BCA) reagent [19]. To extract the intracellular proteins, the G. geotrichum sediment was suspended in a buffer composed of: $25 \mathrm{mM}$ potassium phosphate, $100 \mathrm{mM}$ potassium chloride solution at $\mathrm{pH} 7.0$, and a $10 \%$ glycerol solution. The samples were then mixed on a glass vortex shaker (Sigma Aldrich, Saint Louis, MI, USA). A 1\% solution of Triton X-100 and a 1\% solution of sodium deoxycholate were introduced into the tests. Incubation of the samples was carried out at $4{ }^{\circ} \mathrm{C}$ for $1 \mathrm{~h}$. The samples were then centrifuged to separate the soluble and insoluble fraction of proteins. Soluble proteins from G. geotrichum 38 cells were analyzed by SDS-PAGE and spectrophotometric reagents with BCA reagent. The extracellular and intracellular proteins of G. geotrichum 38 were then subjected to proteolysis using trypsin [20]. Specific peptides obtained from proteolysis were analyzed using UHPLC/MS (Thermo Fischer Scientific, Waltham, MA, USA) and the results compared with the MASCOT database (minimum significant score of $<68$, significance threshold $p<0.05$, ions score or expect cut-off: 30 ). MS data processing was based on Celińska et al. [20]. The analyses were carried out in the laboratory of the Blirt company (Gdańsk, Poland).

\subsection{Determination of Sphingolipid Content}

The method of Singh and Del Poeta [12] was used to determine the content of sphingolipids in the G. geotrichum 38 cell biomass. The samples were frozen at $-20{ }^{\circ} \mathrm{C}$ until needed for analysis. Determinations were carried out in triplicate. Sphingolipid content was determined by reversed phase chromatography using mass spectroscopy. The analysis was carried out on a Dionex UltiMate 3000 Ultra-Performance Liquid Chromatography (UHPLC) (Thermo Fisher Scientific, Waltham, MA, USA) device coupled with an ultrahigh-resolution Bruker maXis (Bruker, Billerica, MA, USA) tandem spectrometer using a quadrupole time-of-flight analyzer. Synergi $4 \mu \mathrm{m}$ Fusion-RP 80 Å column, LC column, $150 \times 3.0 \mathrm{~mm}$ (Phenomenex, Torrance, CA, USA) were used. Water as the mobile phase contained $2 \mathrm{mM} \mathrm{HCOONH}_{4}$ and $0.2 \%$ formic acid (component A). Component $\mathrm{B}$ was methanol with $2 \mathrm{mM} \mathrm{HCOONH}_{4}$ and $0.2 \%$ formic acid. The injection volume was $10 \mu \mathrm{L}$ and the flow rate was $0.3 \mathrm{~mL} / \mathrm{min}$ with an elution gradient of $50 \%$ to $80 \%$ of component B in $10 \mathrm{~min}$, further to $99 \%$ of component B in $20 \mathrm{~min}$, and holding under these conditions for $20 \mathrm{~min}$. The chromatography column was thermostated at $40^{\circ} \mathrm{C}$. To identify compounds, MS spectra were recorded using electrospray ionization (ESI) as the positive ion mode with the electrospray ionization method (target analysis). The mass spectrometer operation parameters with ESI source were capillary voltage at $4500 \mathrm{~V}$, nitrogen nebulization at 1.8 bar pressure, and drying gas flow of $\mathrm{N}_{2}$ at $9 \mathrm{~L} / \mathrm{min}$ at $200{ }^{\circ} \mathrm{C}$. The ionic signal was collected in the $80-1200 \mathrm{~m} / \mathrm{z}$ range. Gradient elution was determined according to the method of Zhang et al. [21]. The ESI-MS system was calibrated using sodium formate salt. The molecular weight standard was introduced at the beginning of chromatographic separation. Data Analysis 4.1 (Bruker Daltonik, Hamburg, Germany) and Profile Analysis (Bruker Daltonik) software were used to analyze the results. 
The chromatogram extracts peaks corresponded to ions of the analyzed compounds $[\mathrm{M}+\mathrm{H}]^{+}[12]$. The compounds found in the samples were identified based on the molecular weight of the parent ion (MS experiment) and on structural information from mass spectrometer (MS/MS experiment).

\subsection{Determination of B Vitamin Content}

The amount of B vitamins synthesized by G. geotrichum 38 in the culture was evaluated by reversed phase chromatography and mass spectroscopy using a Dionex UltiMate 3000 UHPLC device coupled with a Bruker maXis tandem spectrometer. The modified methodology proposed by Zand et al. [22] and a standard of vitamin $B_{2}$ were used. A Kinetex $1.7 \mu \mathrm{m} \mathrm{C18} 100 \AA$ LC column $100 \times 2.1 \mathrm{~mm}$ was used. The mobile phases were $0.1 \%$ formic acid in water (A) and $0.1 \%$ formic acid in acetonitrile (B). Gradient conditions used were: for the first five min, the share of component B was $5 \%$, increasing linearly over $9 \mathrm{~min}$ to $90 \%$. The flow rate was $0.2 \mathrm{~mL} / \mathrm{min}$. The volume of the injected sample was $20 \mu \mathrm{L}$. The column was thermostated at $40{ }^{\circ} \mathrm{C}$. Ionization was carried out using the ESI method in positive ion mode, $[\mathrm{M}+\mathrm{H}]^{+}$(target analysis). The results obtained were read from the Data Analysis 4.1 program. During the MS/MS experiments, compounds were detected using molecular weight and structural information from the detector with the help of the Kyoto Encyclopedia of Genes and Genomes (https://www.genome.jp/kegg/). The analysis was carried out in triplicate.

\subsection{Determination of Sterol Content of G. geotrichum 38 Biomass}

The sterols content of the G. geotrichum 38 biomass was determined according to the method of Perkowski et al. [23]. From the sample, $0.1 \mathrm{~g}$ biomass was taken and $2 \mathrm{~mL}$ of methanol and $0.5 \mathrm{~mL} 2 \mathrm{M}$ $\mathrm{NaOH}$ were added. The test tubes were placed in closed plastic bottles, which were placed inside a microwave oven. The samples were irradiated for $20 \mathrm{~s}$ at a power of $370 \mathrm{~W}$. After $5 \mathrm{~min}$, the process was repeated. After cooling, the samples were neutralized with $1 \mathrm{~mL} 1 \mathrm{M}$ aqueous $\mathrm{HCl}$ and $2 \mathrm{~mL}$ methanol. Extraction was carried out using pentane $(3 \times 4 \mathrm{~mL})$. Methanol was added once the pentane had evaporated. The samples were then treated with ultrasound. The sterols were analyzed using HPLC with a UV detector at a wavelength of $282 \mathrm{~nm}$. A Nova Pak C-18 column $(4 \mu \mathrm{m}, 150 \times 3.9 \mathrm{~mm})$ (Waters, Milford, MA, USA) was used for separation [23]. An ergosterol standard was used. Elution was carried out in a methanol:acetonitrile (90:10) system at a flow rate of $0.6 \mathrm{~mL} / \mathrm{min}$. The volume of the injected sample was $50 \mu \mathrm{L}$. The determinations were carried out in triplicate.

\subsection{Determination of Lipoic Acid Content}

The lipoic acid contents were determined following Chwatko et al. [24]. Each sample was prepared in five replications. A liquid chromatograph from Hewlett-Packard (Palo Alto, CA, USA) was used and separation was carried out on a Zorbax SB-C18 column $(150 \mathrm{~mm} \times 4.6 \mathrm{~mm}, 5 \mu \mathrm{m})$ from Agilent Technologies (Santa Clara, CA, USA), using a gradient elution with the following profile: $0-5$ min: 10\%-40\% B; 5-6 min: $40 \%-10 \%$ B; 6-8 min: $10 \%$ B. Component $A$ of the mobile phase was $2 \%$ acetic acid, while component $B$ was acetonitrile. The column temperature was $25^{\circ} \mathrm{C}$, the mobile phase flow rate was $1 \mathrm{~mL} / \mathrm{min}$ through the column, and the analytical wavelength was $321 \mathrm{~nm}$. The volume of the injected sample was $5 \mu \mathrm{L}$. Lipoic acid was used as a standard.

\subsection{Determination of Trehalose Content of Culture}

The trehalose content of the G. geotrichum 38 culture was determined following the method described by Pawlicka et al. [25]. The cultures were centrifuged at $4500 \mathrm{~g} / 10 \mathrm{~min}$. The supernatant was then decanted, and the cellular biomass was washed with distilled water and again centrifuged $(4500 \mathrm{~g} / 10 \mathrm{~min})$. The pellet was resuspended in $1.6 \mathrm{~mL}$ of an $80 \%$ methanol solution $(\mathrm{v} / \mathrm{v})$. The samples were next incubated for an hour at $60{ }^{\circ} \mathrm{C}$. The samples were analyzed using a HPLC Agilent Technologies 1200. The analysis used a $300 \times 7.8 \mathrm{~mm}$ Rezex ROA column (Phenomenex, Torrance, CA, USA), which was thermostated at $40{ }^{\circ} \mathrm{C}$. A $0.001 \mathrm{M} \mathrm{H}_{2} \mathrm{SO}_{4}$ solution with a flow rate of $0.6 \mathrm{~mL} / \mathrm{min}$ was used as the mobile phase. The volume of the injected sample was $50 \mu \mathrm{L}$. A trehalose standard 
was used to identify the samples and as an external standard to quantify analysis. The samples were analyzed in triplicate.

\subsection{Production of Fried Cottage Cheese Using G. geotrichum 38 and Determination of Vitamin $B_{2}$ and Ergosterol}

Fried cottage cheese was produced by combining cottage cheese with G. geotrichum 38 biomass and leaving the mixture at room temperature for 3 days, before being pan-fried with butter. The production of fried cottage cheese using G. geotrichum 38 has been described by Grygier et al. [4].

The quantity of vitamin $B_{2}$ in milk was determined following Schmidt et al. [26]. $1 \mathrm{M} \mathrm{HCl}$ solution was added dropwise to $10 \mathrm{~mL}$ of milk until a $\mathrm{pH}$ of 4.0 was obtained. Water was then added to a volume of $30 \mathrm{~mL}$. The samples were incubated for $10 \mathrm{~min}$ at $20{ }^{\circ} \mathrm{C}$ with constant shaking. The samples were further centrifuged ( $4000 \mathrm{~g} / 10 \mathrm{~min}$ ) and the resulting supernatant was filtered through a syringe filter $(0.2 \mu \mathrm{m})$. This was measured for the cheese using the methodology described by Stancher and Zonta [27]. To $5 \mathrm{~g}$ of finely chopped fried cheese, obtained after $72 \mathrm{~h}$ of ripening, $7 \mathrm{~mL}$ of methanol:water $(1: 2 \mathrm{v} / \mathrm{v})$ solution was added. The samples were shaken for $4 \mathrm{~min}$, and $3 \mathrm{~mL}$ of glacial acetic acid was added before shaking again. After the samples were centrifuged (2000 g/15 min), the supernatant was transferred to a $20 \mathrm{~mL}$ graduated flask. The remaining precipitate was washed three times with $4 \mathrm{~mL}$ of water:methanol:glacial acetic acid (65:25:10 $\mathrm{v} / \mathrm{v} / \mathrm{v})$. The solution was then added to $20 \mathrm{~mL}$ of the sample. The samples were filtered through a syringe filter $(0.2 \mu \mathrm{L})$. Trials of milk and cheese were performed in triplicate. Chromatographic analysis of vitamin $\mathrm{B}_{2}$ was performed as in Section 2.5. The ergosterol content of cheese was determined in accordance with the methodology described in the Section 2.6.

\section{Results and Discussion}

\subsection{Proteomic Analysis of Proteins Synthesized by G. geotrichum 38}

A total of 27 proteins were extracted and identified from hyphae of G. geotrichum 38 cultured on a medium as described by Bajpai et al. [18]. Table 1 lists the identified molecules. Most of these proteins are molecules involved in the cell division cycle associated with DNA replication. The present study also identified the $\alpha$-subunit of the acetyl-CoA carboxyl transferase protein (ACC); this is an enzyme that catalyzes the carboxylation of acetyl-CoA to malonyl-CoA [28] as the first stage in fatty acid biosynthesis. The resulting malonyl-CoA is used in the synthesis of long-chain fatty acids [28]. In yeast, the deletion of the ACC enzyme gene is lethal. Even the presence of fatty acids in the medium does not allow cell survival in the absence of the ACC enzyme. This confirms the crucial role of the ACC enzyme in the biosynthesis of fatty acids. The synthesized fatty acids may act as components of sphingolipids and ceramides [28]. In the study of Besada-Lombana et al. [29] on the yeast S. cerevisiae, overexpression of the ACC gene guaranteed an increase in the efficiency of fatty acid synthesis, in particular of oleic acid. Also, an increase of lipid content of E. coli cells was found upon overexpression of the ACC enzyme gene [30]. The presence of the ACC enzyme in the fungal cells of G. geotrichum 38 confirms the ability of this microorganism to biosynthesize fatty acids. Grygier et al. [4] demonstrated the ability of G. geotrichum 38 to produce PUFA in culture medium and in fried cottage cheese. The presence of PUFA in the body can help prevent many diseases, particularly those of the circulatory system. The body does not produce PUFA, so they should be taken with food [31]. The confirmation of the production of PUFA by G. geotrichum 38 points the way to preparing dairy products with increased levels of PUFA. 
Table 2. Proteins isolated from hyphae and culture of G. geotrichum 38 that are related to the biosynthesis of bioactive compounds and other metabolites of industrial importance.

\begin{tabular}{cc}
\hline Proteins Extracted from Hyphae & Possible Protein Function \\
\hline $\begin{array}{c}\text { delta(8)-fatty-acid desaturase } \\
\text { pyridoxine biosynthesis PDX1-like protein } \\
\text { saccharopine dehydrogenase } \\
\text { enolase-phosphatase E1 }\end{array}$ & $\begin{array}{c}\text { sphingolipid biosynthesis [52] } \\
\text { biosynthesis of B-group vitamins [53] } \\
\text { lysine biosynthesis [54] } \\
\text { methionine biosynthesis [55] } \\
\text { histidine biosynthesis [56] }\end{array}$ \\
$\begin{array}{cc}\text { imidazole glycerol phosphate synthase hisHF } \\
\text { Proteins Extracted from Culture Fluid }\end{array}$ & Possible Protein Function \\
\hline $\begin{array}{c}\text { pyridoxine biosynthesis PDX1-like protein } \\
\text { uncharacterized protein YMR134W } \\
\text { alpha,alpha-trehalose-phosphate synthase } \\
\text { lipoyl synthase, mitochondrial }\end{array}$ & $\begin{array}{c}\text { biosynthesis of B-group vitamins [53] } \\
\text { ergosterol biosynthesis [57] }\end{array}$ \\
trehalose biosynthesis [58] \\
lipoic acid biosynthesis [59] \\
leucine biosynthesis [60] \\
amino-acid acetyltransferase, mitochondrial \\
a-isopropylmalate biosynthesis [61] \\
probable 5-methyltetrahydropteroyltriglutamatehomocysteine \\
methyltransferase
\end{tabular}

\subsection{Hypothetical Fatty Acid Biosynthesis Pathway}

Certain enzymes found in the proteome of G. geotrichum 38 may be associated with the biosynthesis of fatty acids-namely, citrate ATP lyase and isocitrate dehydrogenase. Acetyl-CoA carboxyl transferase enzyme and aconitase were also found. The biosynthesis of these enzymes is crucial for the production of fatty acids. Aconitase catalyze the conversion of acetyl-CoA to malonyl-CoA, which begins the fatty acid biosynthesis pathway [63]. In G. geotrichum 38, this pathway begins with gluconeogenesis, which requires a carbon source to be available in the nutrient medium. This process involves the enzymatic conversion of nonsaccharide precursors into glucose [63]. Glycerol, derived from rapeseed oil, may act as such a precursor. In glyoxysomes, lipids are transformed into saccharides. This confirms the presence of isocitrate lyase and malate synthase enzymes. The end product of gluconeogenesis is pyruvate, which participates further in the Krebs cycle. The citric acid formed at this stage is converted by ATP citrate lyase to acetyl-CoA, which is used in the synthesis of fatty acids [63]. On the basis of the proteome analysis of the biomass and the supernatant of G. geotrichum 38 culture on a substrate that stimulates PUFA biosynthesis, we can conclude that G. geotrichum 38 possesses a fatty acid biosynthesis pathway. The fatty acid biosynthesis pathway was presented in Figure 1. To date, the proteome of mold has only been described by Wang et al. [64]. Based on proteomic analysis, these researchers characterized the lipid transformation pathway in the mold Mortierella alpina, which has demonstrated the ability to produce fatty acids, triacylglycerols (TAGs), sterols, sphingolipids, and glycerophospholipids. Hamid et al. [65] demonstrated the effect of the enzymes 6-phosphogluconate dehydrogenase, glucose-6-phosphogluconate dehydrogenase, isocitrate dehydrogenase, malic enzyme, citrate ATP lyase, and fatty acid synthase on lipid accumulation in Cunninghamella fungal cells. These enzymes were synthesized under conditions of limited availability of nitrogen compounds. According to Hamid et al. [65], lipogenesis was possible in the presence of all six enzymes, with the activity of citrate ATP citrate, malic enzyme, and fatty acid synthase being particularly important [65]. 


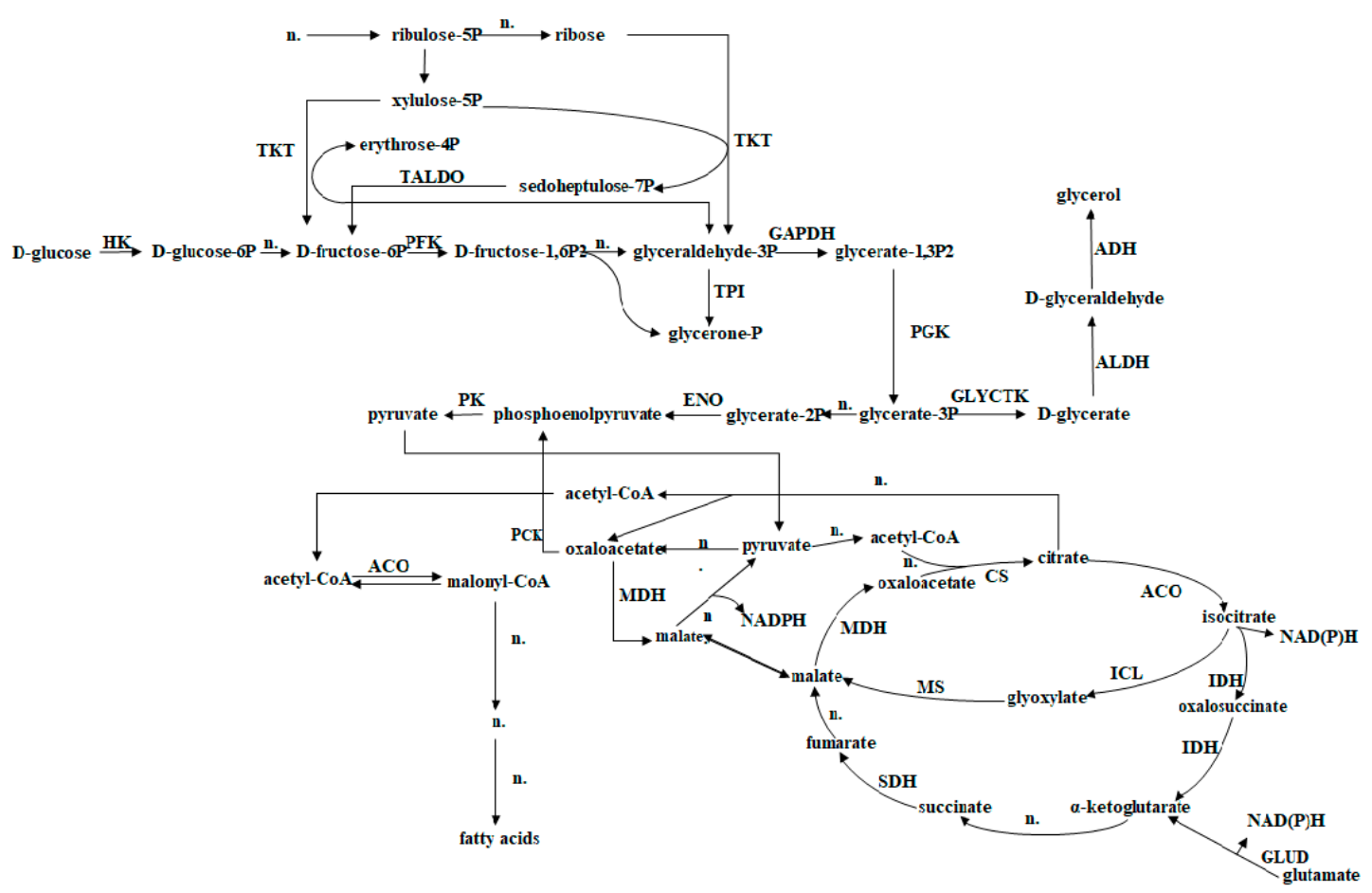

Figure 1. Pathway of fatty acid transformation in G. geotrichum. hexokinase (HK, EC2.7.1.1), transketolase (TKT, EC2.2.1.1), transaldolase (TALDO, EC2.2.1.2), phosphofructokinase (PFK, EC2.7.1.11), glyceraldehyde 3-phosphate dehydrogenase (GAPDH, EC1.2.1.12), phosphoglycerate kinase (PGK, EC2.7.2.3), triose-phosphate isomerase (TPI, EC5.3.1.1), enolase (ENO, EC4.2.1.11), pyruvate kinase (PK, EC2.7.1.40), malate dehydrogenase (MDH, EC1.1.1.37), citrate synthase (CS, EC2.3.3.1), aconitase (ACO, EC4.2.1.3), isocitrate dehydrogenase (IDH. EC1.1.1.41 and EC1.1.1.42), glutamate dehydrogenase (GLUD, EC1.4.1.2 and EC1.4.1.3), phosphoenolpyruvate carboxykinase (PCK, and EC4.1.1.32 EC4.1.1.49), succinate dehydrogenase (SDH EC1.3.5.1), alcohol dehydrogenase (ADH, EC1.1.1.2), phosphoglycerate kinase (GLYCTK, EC2.7.1.31), aldehyde dehydrogenase (ALDH, EC1.2.1.3), isocitrate lyase (ICL, EC4.1.3.1), methionine synthase (MS, EC2.1.1.13), and n.- enzymes, whose content in the sample cannot be identified the method used (own work on the basis of Wang et al. [63]).

\subsection{Sphingolipids in G. geotrichum 38 Culture}

Delta-8-fatty-acid desaturase was found in the proteome of G. geotrichum 38; this is responsible for the introduction of a double bond in long-chain sphingolipids and in fatty acids [52]. The de novo biosynthesis of sphingolipids begins with the condensation of L-serine and palmitoyl-CoA. This allows the production of 3-ketodihydrosfingosine, which is then reduced to dihydrosfingosine. Then, $\Delta-8$ desaturase converts the dihydrosfingosine to $\Delta 4$-ceramide; $\Delta 4, \Delta 8$-ceramide (skeleton d18:2, 4,8-sphingodienyes) [11]. We searched the G. geotrichum 38 samples for the sphingolipids identified in other fungi species cultures [12]. Based on ion molecular weight, seven sphingolipids were found: 4-sphingenine (d18:1), phytosphingosine (t18:0), 4,8-sphingadiene (d18:2), 9-methyl-4,8-sphingadiene (d19:2), 4-amino-9-methyl-4,8-nonadecadiene-1,3-diol (d20:2), 4-hydroxy-9-methyl-1-4,8-sphingadiene $(\mathrm{d} 19: 2 \mathrm{OH}), 4$-amino-9-methyl-8-nonadecene-1,3,4-triol (d20:1). The percentage occurrence of each is shown in Table 3. The profile was dominated by 4-amino-9-methyl-8-nonadecene-1,3,4-triol (d20:1). The levels sphingolipids were measured twice in order to determine any quantitative changes that occurred during culturing. During culturing of G. geotrichum 38, the percentage of 4-sphingenine, phytosphingosine, and 4-amino-9-methyl-8-nonadecene-1,3,4-triol increased. In those samples, the levels of 4,8-sphingadiene, 9-methyl-4,8-sphingadiene, 4-amino-9-methyl-4,8-nonadecadiene-1,3-diol, and 4-hydroxy-9-methyl-1-4,8-sphingadiene decreased in the sphingolipid profile with increasing culture time. This may have been due to the use of glycerol from these compounds for the esterification 
of de novo fatty acids [66]. As seems to be the case from the available literature, microorganisms synthesize mainly 9-methyl-4,8-sphingadiene. The main producers of this compound are Cryptococcus spp., Aspergillus spp., and Candida spp. [12].

Table 3. Percentage of individual sphingolipids G. geotrichum 38 (1.) 4-sphingenine (d18:1), (2.) phytosphingosine (t18:0), (3.) 4,8-sphingadiene (d18:2), (4.) 9-methyl-4,8-sphingadiene (d19:2), (5.) 4-amino-9-methyl-4,8-nonadecadiene-1,3-diol (d20:2), (6.) 4-hydroxy-9-methyl 1-4,8-sphingadiene (d19:2 $\mathrm{OH})$, (7.) 4-amino-9-methyl-8-nonadecene-1,3,4-triol (d20:1)).

\begin{tabular}{cccccccc}
\hline \multicolumn{7}{c}{ Sphingolipid \{\%\} } \\
\hline Culture Time (h) & $\mathbf{( 1 . )}$ & $\mathbf{( 2 . )}$ & $\mathbf{( 3 . )}$ & $\mathbf{( 4 . )}$ & $\mathbf{( 5 . )}$ & (6.) & (7.) \\
\hline 48 & $25.7^{\mathrm{a}} \pm 1.0$ & $0.2^{\mathrm{a}} \pm 0.0$ & $1.1^{\mathrm{a}} \pm 0.0$ & $0.5^{\mathrm{b}} \pm 0.0$ & $8.7^{\mathrm{b}} \pm 0.1$ & $3.0^{\mathrm{b}} \pm 0.0$ & $60.8^{\mathrm{a}} \pm 1.7$ \\
216 & $28.2^{\mathrm{b}} \pm 0.3$ & $0.9^{\mathrm{b}} \pm 0.0$ & $0.6^{\mathrm{a}} \pm 0.1$ & $0.2^{\mathrm{a}} \pm 0.0$ & $5.9^{\mathrm{a}} \pm 0.1$ & $0.3^{\mathrm{a}} \pm 0.0$ & $63.9^{\mathrm{b}} \pm 0.5$ \\
\hline
\end{tabular}

Different letters within columns indicate significant differences at $\alpha=0.05$.

\subsection{Determination of B-Group Vitamins in G. geotrichum 38 Culture}

A pyridoxine biosynthesis PDX1-like enzyme was found in the proteome of G. geotrichum 38 , which is responsible for the biosynthesis of vitamin $\mathrm{B}_{6}$. Analysis confirmed the presence of vitamin $B_{6}$, though this was derived from yeast extract-no increase occurred in the amount of vitamin $B_{6}$ during cultivation. We did, however, find an increase in vitamin $B_{2}$, whose precursor is guanosine-5'-triphosphate (GTP). The GTPase activating enzymes were present in the proteome of G. geotrichum 38. In mold, whose carbon source is fatty acids, biosynthesis begins in the peroxisomes. The glyoxylate cycle transforms it into GTP. GTP with serine are involved in three reactions that lead to the synthesis of 6,7-dimethyl-8-ribityllumazine. This compound is a precursor to vitamin $B_{2}$ in the last stage of biosynthesis [67].

Table 4 presents the results of the yield determination of vitamin $B_{2}$ biosynthesis by G. geotrichum 38. In the medium, at the start of G. geotrichum 38 culture, there was an average of $92 \mu \mathrm{g} / \mathrm{L}$ vitamin $\mathrm{B}_{2}$, derived from yeast extract. This value increased during the culture. After $216 \mathrm{~h}$ in the culture, $224 \mu \mathrm{g} / \mathrm{L}$ of vitamin B2 was obtained.

Table 4. Vitamin $B_{2}$ content of G. geotrichum 38 culture.

\begin{tabular}{cc}
\hline Culture Time $\{\mathbf{h}\}$ & Vitamin B2 Content $\mu \mathrm{g} / \mathrm{L}$ \\
\hline 0 & $92^{\mathrm{a}} \pm 4$ \\
\hline 216 & $224^{\mathrm{b}} \pm 10$ \\
\hline
\end{tabular}

Different letters within columns indicate significant differences at $\alpha=0.05$.

Similar trends were also observed by Stahmann et al. [68]. Mold of the species Ashbya gossypii was grown on nutrients supplemented with vegetable oil. This favored the biosynthesis of vitamin $B_{2}$ by Ashbya spp. [68]. Optimal conditions for the overproduction of vitamin $\mathrm{B}_{2}$ by Ashbya gossypii included a temperature of $26-28{ }^{\circ} \mathrm{C}$ and oxygenation of the culture. Initially, the average yield of vitamin $B_{2}$ by Ashbya gossypii was $200 \mathrm{mg} / \mathrm{L}$.

\subsection{Determination of Sterols in G. geotrichum 38 Biomass}

Analysis of the G. geotrichum 38 proteome revealed the presence of the protein YMR134W, which participates in ergosterol biosynthesis. In mold, the biosynthesis of ergosterol begins with the transformation of acetyl-CoA into isopentyl pyrophosphate. After the condensation reaction and the addition of further molecules of isopentyl pyrophosphate, squalene (a sterol precursor) is produced. Enzymes of the cytochrome P450 group are required in the biosynthesis of ergosterol [9]. Ergosterol was also found in the hyphae of G. geotrichum 38. In $96 \mathrm{~h}$ of culture, its yield within the cells was on average $54.63 \mathrm{mg} / \mathrm{kg}$ of dry biomass. Contreras et al. [69] examined the yeast Xanthophyllomyces dendrorhous for ergosterol production. The maximum ergosterol yield in the strains they tested was 
$4.21 \mathrm{mg} / \mathrm{g}$ of dry biomass [69]. Effective ergosterol biosynthesis is also possible using Saccharomyces cerevisiae and S. uvarum [8,70]. Nahlik et al. [8] found that the amount of ergosterol obtained depends on the final amount of cellular biomass. In this study, ergosterol production also increased with oxidative stress. The studied microorganisms were cultured on a medium supplemented with glucose and ethanol, which resulted in three times higher ergosterol values in culture $\left(103.84 \times 10^{-6} \mathrm{~g} / \mathrm{L} \mathrm{h}\right)$ than in the control sample [8].

\subsection{Determination of Lipoic Acid Content of G. geotrichum 38 Culture}

Levels of lipoic acid in microorganisms are correlated with their metabolic activity. Higher levels of lipoic acid are found when a pyruvate dehydrogenase complex is present in the cell. The main function of lipoic acid is thus to oxidatively decarboxylate pyruvate. In some microorganisms, it can degrade branched chain amino acids. A number of saprophytic food microorganisms exhibit the potential for lipoic acid biosynthesis; these are mainly representatives of the genera Bacillus, Pseudomonas, Pedicoccus, Rhodospirillum, Anacystis, Gloecaps, Nostoc, and Saccharomyces [71]. Mitochondrial lipoyl synthase enzyme was found, in the proteome of G. geotrichum 38; this is responsible for the synthesis of lipoic acid. However, no lipoic acid was found in the culture of G. geotrichum 38. It is possible that lipoic acid does not occur freely in cells, but is connected by an amide bond to the amino group of lysine found in proteins [72].

\subsection{Determination of the Trehalose Content of G. geotrichum 38 Culture}

The enzyme alpha,alpha-trehalose-phosphate synthase was found in the proteome of G. geotrichum 38. This enzyme catalyzes the transfer of glucose from uridine diphosphate (UDPglucose) to glucose-6-phosphate to form trehalose-6-phosphate. This step is followed by the hydrolysis of trehalose-6-phosphate to trehalose. The enzyme trehalose-6-phosphate phosphatase is involved in the above process [15]. The trehalose content of the culture systematically increased, and after $168 \mathrm{~h}$ of culture had reached $0.91 \mathrm{~g} / \mathrm{L}$ (Figure 2). One microorganism known to be capable of biosynthesizing trehalose is Propionibacterium spp. The agents that stimulates trehalose biosynthesis by Propionibacterium spp. are lactose [73] and glycerol [74].

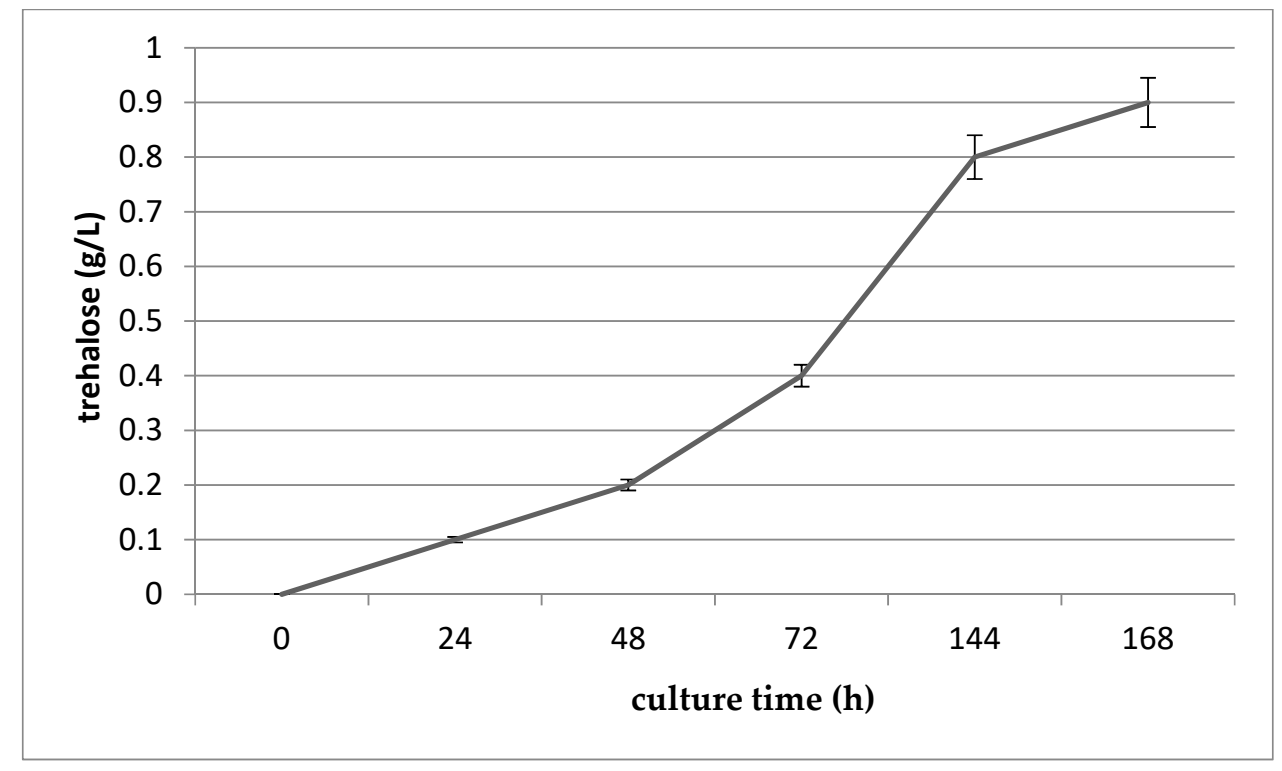

Figure 2. Trehalose content of G. geotrichum 38 culture.

\subsection{Vitamin $B_{2}$ and Ergosterol in Fried Cottage Cheese Produced by G. geotrichum 38}

The above experiments suggested determining vitamin $\mathrm{B}_{2}$ and ergosterol in a model food product, in a technological process used for the studied microorganisms. These compounds were determined in 
fried cottage cheese prepared after five days of digestion. Raw milk may also be a source of vitamin $\mathrm{B}_{2}$ in food products [27]. The levels of this compound were also evaluated in the raw material used in the technological process. In the experiments, the vitamin $B_{2}$ content of the raw milk was $1.19 \mu \mathrm{g} / \mathrm{g}$ milk. The amount of the compound in fried cheese doubled, reaching an average of $3.50 \mu \mathrm{g} / \mathrm{g}$ cheese. The increase in this compound in the fried cottage cheese was most likely associated with the biosynthesis of vitamin $B_{2}$ by G. geotrichum 38. In studies carried out on cheese produced in Italy, the vitamin $B_{2}$ content ranged from 1.17 to $3.75 \mathrm{~g} / \mathrm{g}$ of cheese [28]. The presence of ergosterol was also evaluated in fried cottage cheese, confirming the presence of ergosterol in the model food product. The amount of this compound in the final product was $0.78 \mathrm{mg} / \mathrm{kg}$ of cheese on average. To date, the presence of ergosterol in food products has been associated with food contamination with pathogenic microflora. The literature on the subject, however, lacks information describing the effect of starter and nonstarter microorganisms on increasing the ergosterol content of food. The fatty acid content has been presented in Grygier et al. [4]. No lipoic acid was determined in the fried cheese due to it being absent from the culture.

\section{Conclusions}

In this study, we carried out proteomic analysis of a G. geotrichum 38 culture and selected those proteins that can participate in the biosynthesis of bioactive compounds (delta(8)-fatty-acid desaturase, pyridoxine biosynthesis PDX1-like protein, uncharacterized protein YMR134W, alpha,alpha-trehalose-phosphate synthase, lipoyl synthase, mitochondrial). G. geotrichum produced lipids containing long-chain polyunsaturated fatty acids. Additionally, we demonstrated the biosynthesis of vitamin $B_{2}$, ergosterol, sphingolipids, and trehalose by G. geotrichum 38 . When G. geotrichum 38 was used to prepare model fried cottage cheese, increases were seen in vitamin $\mathrm{B}_{2}$ and ergosterol levels. These results increase our knowledge of the potential of G. geotrichum to produce bioactive compounds and demonstrate the possibility of using it in the production of food products.

Author Contributions: Conceptualization, A.G., K.M. and M.R.; Data curation, A.G.; Formal analysis, A.G.; Funding acquisition, A.G.; Investigation, A.G.; Methodology, A.G., K.M., A.S., K.S.-S., J.P.-K., G.C. and M.R.; Project administration, A.G.; Resources, A.G.; Software, A.S., K.S.-S., J.P.-K. and G.C.; Supervision, A.G.; Validation, K.M., A.S., K.S.-S., J.P.-K. and G.C.; Writing—original draft, A.G., K.M. and M.R.; Writing-review \& editing, A.G., K.M. and M.R.

Funding: This research was funded by the National Science Centre, Poland, grant number 2015/17/N/NZ9/00960.

Conflicts of Interest: The authors declare no conflict of interest.

\section{References}

1. Shukla, R. Studies on bioactive compounds from different microorganisms. Int. J. Sci. Eng. Res. 2015, 6, 1225-1233.

2. Chaves-Lopez, C.; Serio, A.; Rossi, C.; Pepe, A.; Compagnone, E.; Paparella, A. Interaction between Galactomyces geotrichum KL20B, Lactobacillus plantarum LAT3 and Enterococcus faecalis KE06 during milk fermentation. Fermentation 2017, 3, 52. [CrossRef]

3. Grygier, A.; Myszka, K.; Rudzińska, M. Galactomyces geotrichum: Moulds from dairy products with high biotechnological potential. Acta Sci. Pol. Tecnol. Aliment. 2017, 16, 5-16. [CrossRef]

4. Grygier, A.; Myszka, K.; Juzwa, W.; Białas, W.; Rudzińska, M. Ability of Galactomyces geotrichum for production of fatty acids. Folia Microbiol. under review.

5. Szczepańska, E.; Robak, M. Proteomika w badaniu drobnoustrojów. Acta Sci. Pol. Biotech. 2013, 12, 25-40.

6. Ledesma-Amaro, R.; Santos, M.A.; Jiménez, A.; Revuelta, J.L. Microbial production of vitamins. In Microbial Production of Food Ingredients, Enzymes and Nutraceuticals, 1st ed.; McNeil, B., Archer, D., Eds.; Woodhead Publishing: Cambridge, UK, 2013; pp. 571-594.

7. Fogle, K.J.; Parson, K.G.; Dahm, N.A.; Holmes, T.C. Cryptochrome is a blue-light sensor that regulates neuronal firing rate. Science 2011, 6023, 1409-1413. [CrossRef] [PubMed] 
8. Nahlik, J.; Hrncirik, P.; Mares, J. Towards the design of an optimal strategy for the production of ergosterol from Saccharomyces cerevisiae yeasts. Biotechnol. Prog. 2017, 33, 838-848. [CrossRef] [PubMed]

9. Sułkowska-Ziaja, K.; Hałaszuk, P.; Mastej, M.; Piechaczek, M.; Muszyńska, B. Mycosteroles: Characteristics and biological importance. Med. Internacia Revuo 2016, 106, 26-34.

10. Ostlund, R.E.; Racette, S.B.; Stenson, W.F. Effects of trace components of dietary fat on cholesterol metabolism: Phytosterols, oxysterols, and squalene. Nutr. Rev. 2002, 60, 349-359. [CrossRef] [PubMed]

11. Chalfant, C.; Del Poeta, M. Sphingolipids as Signaling and Regulatory Molecules, 1st ed.; Springer Science+Business Media: New York, NY, USA, 2010.

12. Singh, A.; Del Poeta, M. Sphingolipidomics: An important mechanistic tool for studying fungal pathogens. Front. Microbiol. 2016, 7, 501. [CrossRef] [PubMed]

13. Vesper, H.; Schmelz, E.M.; Nikolova-Karakashian, M.N.; Dillehay, D.L.; Lynch, D.V.; Merrill, A.H. Sphingolipids in food and the emerging importance of sphingolipids to nutrition. J. Nutr. 1999, 129, 1239-1250. [CrossRef] [PubMed]

14. Baker, H.; Deangelis, B.; Baker, E.R.; Hutner, S.H. A practical assay of lipoate in biologic fluids and liver in health and disease. Free Radic. Biol. Med. 1998, 25, 473-479. [CrossRef]

15. Chen, Q.; Haddad, G.G. Role of trehalose phosphate synthase and trehalose during hypoxia: From flies to mammals. J. Exp. Biol. 2004, 207, 3125-3129. [CrossRef] [PubMed]

16. Deesuth, O.; Laopaiboon, P.; Laopaiboon, L. High ethanol production under optimal aeration conditions and yeast composition in a very high gravity fermentation from sweet sorghum juice by Saccharomyces cerevisiae. Ind. Crop Prod. 2016, 92, 263-270. [CrossRef]

17. Bald, E.; Sypniewski, S.; Drzewoski, J.; Stępień, M. Application of 2-halopyridinium salts as ultraviolet derivatization reagents and solid-phase extraction for determination of captopril in human plasma by high-performance liquid chromatography. J. Chromatogr. B 1996, 681, 283-289. [CrossRef]

18. Bajpai, P.; Bajpai, P.K.; Ward, O.P. Eicosapentaenoic acid (EPA) formation: Comparative studies with Mortierella strains and production by Mortierella elongate. Mycol. Res. 1996, 95, 1294-1298. [CrossRef]

19. Smith, P.K.; Krohn, R.I.; Hermanson, G.T.; Mallia, A.K.; Gartner, F.H.; Provenzano, M.D.; Fujimoto, E.K.; Goeke, N.M.; Olson, B.J.; Klenk, D.C. Measurement of protein using bicinchoninic acid. Anal. Biochem. 1985, 150, 76-85. [CrossRef]

20. Celińska, E.; Olkowicz, M.; Grajek, W. L-Phenylalanine catabolism and 2-phenylethanol synthesis in Yarrowia lipolytica-Mapping molecular identities through whole-proteome quantitative mass spectrometry analysis. FEMS Yeast Res. 2015, 15. [CrossRef]

21. Zhang, W.; Quinn, B.; Barnes, S.; Grabowski, G.; Sun, Y.; Setchell, K. Metabolic profiling and quantification of sphingolipids by liquid chromatography-tandem mass spectrometry. J. Glycomics Lipidomics 2013, 3, 170. [CrossRef]

22. Zand, N.; Chowdhry, B.Z.; Pullen, F.S.; Snowden, M.J.; Tetteh, J. Simultaneous determination of riboflavin and pyridoxine by UHPLC/LC-MS in UK commercial infant meal food products. Food Chem. 2012, 135, 2743-2749. [CrossRef] [PubMed]

23. Perkowski, J.; Wiwart, M.; Buśko, M.; Laskowska, M.; Berthiller, F.; Kandler, W.; Krska, R. Fusarium toxins and total fungal biomass indicators in naturally contaminated wheat samples from north-eastern Poland in 2003. Food Addit. Contam. 2007, 24, 1292-1298. [CrossRef] [PubMed]

24. Chwatko, G.; Krawczyk, M.; Iciek, M.; Kamińska, A.; Bilska-Wilkosz, A.; Marcykiewicz, B.; Głowacki, R. Determination of lipoic acid in human plasma by high-performance liquid chromatography with ultraviolet detection. Arab. J. Chem. 2016. [CrossRef]

25. Pawlicka, J.; Drożdżyńska, A.; Kośmider, A.; Czaczyk, K. Wpływ buforu fosforanowego na produkcje biomasy, kwasu propionowego i trehalozy przez Propionibacterium freudenreichii ssp. shermanii 1. EPISTEME. Czasopismo Naukowo Kulturalne 2015, 26, 85-93.

26. Schmidt, A.; Schreiner, M.G.; Mayer, H.K. Rapid determination of the various native forms of vitamin $B_{6}$ and $\mathrm{B}_{2}$ in cow's milk using ultra-high performance liquid chromatography. J. Chromatog. A 2017, 1500, 89-95. [CrossRef] [PubMed]

27. Stancher, B.; Zonta, F. High performance liquid chromatographic analysis of riboflavin (vitamin $B_{2}$ ) with visible absorbance detection in Italian cheeses. J. Food Sci. 1986, 51, 857-858. [CrossRef]

28. Tong, L. Acetyl-coenzyme A carboxylase: Crucial metabolic enzyme and attractive target for drug discovery. Cell. Mol. Life Sci. 2005, 62, 1784-1803. [CrossRef] [PubMed] 
29. Besada-Lombana, P.; Fernandez-Moya, R.; Fenster, J.; Da Silva, N.A. Engineering Saccharomyces cerevisiae fatty acid composition for increased tolerance to octanoic acid. Biotechnol. Bioeng. 2017, 114, 1531-1538. [CrossRef] [PubMed]

30. Meng, X.; Yang, J.; Cao, Y.; Li, L.; Jiang, X.; Xu, X.; Liu, W.; Xian, M.; Zhang, Y. Increasing fatty acid production in E. coli by simulating the lipid accumulation of oleaginous microorganisms. J. Ind. Microbiol. Biot. 2011, 38, 919-925. [CrossRef] [PubMed]

31. Simopoulus, A.P. Omega-3 fatty acids in inflammation and autoimmution disease. J. Am. Coll. Nutr. 2002, 21, 495-505. [CrossRef]

32. Okamoto, T.; Sekiyama, N.; Otsu, M.; Shimada, Y.; Sato, A.; Nakanishi, S.; Jingami, H. Expression and purification of the extracellular ligand binding region of metabotropic glutamate receptor subtype 1. J. Biol. Chem. 1998, 273, 13089-13096. [CrossRef] [PubMed]

33. Sofia, H.J.; Chen, G.; Hetzler, B.G.; Reyes-Spindola, J.F.; Miller, N.E. Radical SAM, a novel protein superfamily linking unresolved steps in familiar biosynthetic pathways with radical mechanisms: Functional characterization using new analysis and information visualization methods. Nucleic Acid Res. 2001, 29, 1097-1106. [CrossRef] [PubMed]

34. Rosas-Sandoval, G.; Ambrogelly, A.; Rinehart, J.; Wei, D.; Cruz-Vera, L.R.; Graham, D.E.; Stetter, K.O.; Guarneros, G.; Söll, D. Orthologs of a novel archaeal and of the bacterial peptidyl-tRNA hydrolase are nonessential in yeast. Proc. Natl. Acad. Sci. USA 2002, 99, 16707-16712. [CrossRef] [PubMed]

35. UniProt. Available online: https:/ / www.uniprot.org/uniprot/A0A2T5P0V1 (accessed on 10 February 2019).

36. UniProt. Available online: https://www.uniprot.org/uniprot/P09980 (accessed on 10 February 2019).

37. UniProt. Available online: https://www.uniprot.org/uniprot/Q9FVX1 (accessed on 10 February 2019).

38. UniProt. Available online: https:/ / www.uniprot.org/uniprot/Q92II9 (accessed on 10 February 2019).

39. UniProt. Available online: https:/ / www.uniprot.org/uniprot/U5QN56 (accessed on 10 February 2019).

40. UniProt. Available online: https://www.uniprot.org/uniprot/A0A2T3QGM2 (accessed on 10 February 2019).

41. UniProt. Available online: https://www.uniprot.org/uniprot/A0A0F2KUL7 (accessed on 10 February 2019).

42. UniProt. Available online: https://www.uniprot.org/uniprot/A7NPP8 (accessed on 10 February 2019).

43. Sreekumar, P.G.; Hinton, D.R.; Kannan, R. Methionine sulfoxide reductase A: Structure, function and role in ocular pathology. World J. Biol. Chem. 2011, 2, 184-192. [CrossRef] [PubMed]

44. UniProt. Available online: https://www.uniprot.org/uniprot/Q8EQ75 (accessed on 10 February 2019).

45. UniProt. Available online: https:/ / www.uniprot.org/uniprot/B7L440 (accessed on 10 February 2019).

46. UniProt. Available online: https://www.uniprot.org/uniprot/C4ZRR2 (accessed on 10 February 2019).

47. UniProt. Available online: https://www.uniprot.org/uniprot/WOM2E9 (accessed on 10 February 2019).

48. UniProt. Available online: https:/ /www.uniprot.org/uniprot/P0ABM9 (accessed on 10 February 2019).

49. UniProt. Available online: https://www.uniprot.org/uniprot/E8W756 (accessed on 10 February 2019).

50. UniProt. Available online: https://www.uniprot.org/uniprot/B9MG17 (accessed on 10 February 2019).

51. Du, C.; Wenzel, G.P. Mining for microbial gems: Integrating proteomics in the postgenomic natural product discovery pipeline. Proteomics 2018, 18. [CrossRef] [PubMed]

52. Wallis, J.G.; Browse, J. The $\Delta 8$-desaturase of Euglena gracilis: An alternate pathway for synthesis of 20-carbon polyunsaturated fatty acids. Arch. Biochem. Biophys. 1999, 365, 307-316. [CrossRef] [PubMed]

53. UniProt. Available online: https:/ /www.uniprot.org/uniprot/A0A0Y9XSK8 (accessed on 10 February 2019).

54. Kumar, V.P.; West, A.H.; Cook, P.F. Supporting role of lysine 13 and glutamate 16 in the acid-base mechanism of saccharopine dehydrogenase from Saccharomyces cerevisiae. Arch. Biochem. Biophys. 2012, 522, 57-61. [CrossRef] [PubMed]

55. UniProt. Available online: https://www.uniprot.org/uniprot/P32626 (accessed on 10 February 2019).

56. UniProt. Available online: https://www.uniprot.org/uniprot/P33734 (accessed on 10 February 2019).

57. UniProt. Available online: https://www.uniprot.org/uniprot/P40207 (accessed on 10 February 2019).

58. UniProt. Available online: https:/ / www.uniprot.org/uniprot/Q92410 (accessed on 10 February 2019).

59. UniProt. Available online: https://www.uniprot.org/uniprot/P32875 (accessed on 10 February 2019).

60. Miyazaki, K. Bifunctional isocitrate-homoisocitrate dehydrogenase: A missing link in the evolution of $\beta$-decarboxylating dehydrogenase. Biochem. Bioph. Res. Co. 2005, 331, 341-346. [CrossRef] [PubMed]

61. UniProt. Available online: https:/ / www.uniprot.org/uniprot/P0CM18 (accessed on 10 February 2019). 
62. Hego, E.; Bes, C.M.; Bedon, F.; Palagi, P.M.; Chaumeil, P.; Barré, A.; Claverol, S.; Dupuy, J.W.; Bonneu, M.; Lalanne, C.; et al. Differential accumulation of soluble proteins in roots of metallicolous and nonmetallicolous populations of Agrostis capillaris L. exposed to Cu. Proteomics 2014, 14, 1746-1758. [CrossRef] [PubMed]

63. Hames, B.D.; Hooper, N.M. Krótkie wykłady. Biochemia, 3rd ed.; Wydawnictwo Naukowe PWN: Warszawa, Poland, 2004.

64. Wang, L.; Chen, W.; Feng, Y.; Ren, Y.; Gu, Z.; Chen, H.; Wang, H.; Thomas, M.J.; Zhang, B.; Berquin, I.M.; et al. Genome characterization of the oleaginous fungus Mortierella alpina. PLoS ONE 2011, 6, e28319. [CrossRef] [PubMed]

65. Hamid, A.A.; Mokhtar, N.F.; Taha, E.M.; Omar, O.; Yusoff, W.M.W. The role of ATP citrate lyase, malic enzyme and fatty acid synthase in the regulation of lipid accumulation in Cunninghamella sp. 2A1. Ann. Microbiol. 2011, 61, 463-468. [CrossRef]

66. Papanikolaou, S.; Aggelis, G. Lipids of oleaginous yeasts. Part I: Biochemistry of single cell oil production. Eur. J. Lipid Sci. Techol. 2011, 113, 1031-1051. [CrossRef]

67. Alosta, H.A. Riboflavin Production by Encapsulated Candida flareri. PhD. Thesis, University of Oklahoma, Norman, OK, USA, 2007.

68. Stahmann, K.P.; Revuelta, J.L.; Seulberger, H. Three biotechnical processes using Ashbya gossypii, Candida famata, or Bacillus subtilis compete with chemical riboflavin production. Appl. Microbiol. Biot. 2000, 53, 509-516. [CrossRef]

69. Contreras, G.; Barahona, S.; Sepúlveda, D.; Baeza, M.; Cifuentes, V.; Alcaíno, J. Identification and analysis of metabolite production with biotechnological potential in Xanthophyllomyces dendrorhous isolates. World J. Microb. Biot. 2015, 31, 517-526. [CrossRef] [PubMed]

70. Vandamme, E.J. Production of vitamins, coenzymes and related biochemicals by biotechnological processes. J. Chem. Technol. Biot. 1992, 53, 313-327. [CrossRef]

71. Herbert, A.A.; Guest, J.R. Lipoic acid content of Escherichia coli and other microorganisms. Arch. Microbiol. 1975, 106, 259-266. [CrossRef] [PubMed]

72. Borowczyk, K.; Krawczyk, M.; Kubalczyk, P.; Chwatko, G. Determination of lipoic acid in biological samples. Bioanalysis 2015, 14, 1785-1798. [CrossRef] [PubMed]

73. Cardoso, F.S.; Gaspar, P.; Hugenholtz, J.; Ramos, A.; Santos, H. Enhancement of trehalose production in dairy Propionibacteria through manipulation of environmental conditions. Int. J. Food Microbiol. 2004, 91, 195-204. [CrossRef]

74. Pawlicka-Karczorowska, J.; Czaczyk, K. Effect of crude and pure glycerol on biomass production and trehalose accumulation by Propionibacterium freudenreichii ssp. shermanii 1. Acta Biochim. Pol. 2017, 64, 621-629. [CrossRef] [PubMed]

(C) 2019 by the authors. Licensee MDPI, Basel, Switzerland. This article is an open access article distributed under the terms and conditions of the Creative Commons Attribution (CC BY) license (http://creativecommons.org/licenses/by/4.0/). 